\title{
Design environment analysis on a portable handwash station: A case study in Lengkong sub-district, Bandung
}

\author{
S. Salayanti \& W. Prihantoro \\ School of Creative Industries, Telkom University, Bandung, West Java, Indonesia \\ L.H. Penta \\ Sekolah Tinggi Desain Indonesia, Bandung, West Java, Indonesia
}

\begin{abstract}
The Lengkong Sub-District, located on the south side of Bandung, is a very crowded sub-district. With how dense the population of it, the people in Lengkong have the indirect responsibility of keeping themselves and others safe amid the COVID-19 pandemic. Notably, this applies to those who work in the Sub-District Office, as well as those whose work involves going in and out of the Sub-District Office building. To prevent further spreading of the virus, the writer intends to provide the necessary facility for people to wash their hands, as well as to create a campaign icon/symbol to encourage people to wash their hands diligently. This campaign is directed not only to the people who work in the Sub-District Office, but also to all the citizens of Lengkong. The design of this portable handwashing station is made to be as attractive as possible for whoever passes by. The hope is that if they see it, they will have the urge and motivation to wash their hands. The design is also made with the health protocol in mind, with necessary features added to minimalize contamination.
\end{abstract}

Keywords: COVID-19, Lengkong Sub-District Office, portable handwash

\section{INTRODUCTION}

The Lengkong Sub-District office is located at Talaga Bodas Street No. 35, Malabar, Lengkong, Bandung City, West Java. In addition to the workers working in the office, Lengkong citizens also come to the office for several administration services, making it a high traffic location, in which virus spread is especially vulnerable. In this trying time of the COVID-19 pandemic, places like this should have the appropriate facility to accommodate the prevention of virus spread in order to protect not only those who work in the office, but also the civilians coming to the area for the governmental administration services.

One of the simplest facilities supporting the prevention of the virus spread is a place for people to wash their hands. Although they can do this in the washroom in regular circumstances, more facilities are needed in more places to encourage easier access to more frequent handwashing. In this special circumstance, the design of these handwashing posts should be adjusted to fit in the requirements for the purpose to be fulfilled.

Design environment is a systematic approach to evaluate the environmental consequences of a product and its processes, as well as the impact of said product to human engineering and environment (Calori \& Vanden-Eynden 2015). Based on the understanding of what is needed, option analysis, and the available resources for a fast production that also considers the product handling and a cradle-to-grave production. The main focus is the content identification and the environmental implication of the product's development and the life cycle towards the environment (Fiksel 1996).

The purpose of design environment is to create a healthier environment for the worker, the civilians, and also the ecosystem. This program fulfills this purpose by promoting a change of 
technique in how the company manages environmental awareness. The fundamentals of design environments are:

1. fixing the safety of the workers, civilians, and the environment while maintaining the performance and the quality of the product. Another way to put it is to lessen the risk on the workers, civilians, and the environment;

2. using the resources responsibly; and

3. merging the environmental considerations into a product design, product redesign, process, and management.

With the fundamentals of the design environment listed above, there are some examples that can be done to fix a design to be more environmentally aware. The first example is the use of environmentally friendly materials. Be it materials with low use of energy, non-toxic materials, ozone-friendly materials, or a recycled material obtained from the waste of other manufacture process. The second is to use a recyclable resource. Plant and animal produce-based materials is a great example for that, with the provision that these resources should be extracted with conservation in mind. The third example is to use materials with minimal energy and water input, the fourth is to minimalize distribution impact by reducing the product's size and weight, the fifth being the minimalization of resource output like energy and water that will be used by the product during its life, and the sixth and final example is to maximize the durability and longevity of the final product, making parts that could be fixed without scraping everything and making them as recyclable parts.

With the efforts of making a product using the design environment approach gives both the manufacturing process and the final products some advantages. Some of these advantages include not only a product that is environmentally friendly, but also that the final products tend to be a better quality and to add to that, the price of manufacturing could be reduced significantly if the designer choose to use recycled material and/or use reasonable transport option, given the reduced size and weight. It will also appeal to a more environmentally conscious community as well as encourage other to be more conscious of it.

The most common applications of design environment are:

1. recyclable design,

2. knock-down design,

3. energy efficient design,

4. remanufactured design,

5. disposability design, and

6. minimalization of hazardous materials.

Other than the effect on the ecosystem, the design should also mind the effect on the users as members of society. Supporting the main function of the product and beyond, or in this case to promote the habit of handwashing beyond the main function of merely being a facility to do it. Educating the users to a better habit for the sake of not only the user's, but especially in this pandemic, the health of other people who have to make physical contact with the user.

\section{METHOD}

The execution of this research was done with the academic procedure generally applicable in this field of study, which is a qualitative method by observation and literature study about design environment. Although, due to the circumstances of this COVID-19 pandemic, all steps are done online to obey the current health protocol by the time this research was conducted.

Observations and interviews are directed toward the members of the local government institution and to the targeted local civilians. These data were then analyzed to design and produce the proper portable handwashing station. 


\section{RESULTS AND DISCUSSION}

With the condition of the COVID -19 pandemic, this portable handwashing station should comply with the health department's protocol in order to support it, although at the same time, it needs to give the impression that is representative of the local environment without losing its main purpose. To educate the society of the healthy habit of frequent proper handwashing, it is also important to not only put an educational poster near it to display the diagram of proper handwashing, but to also put the supporting facility to act it out.

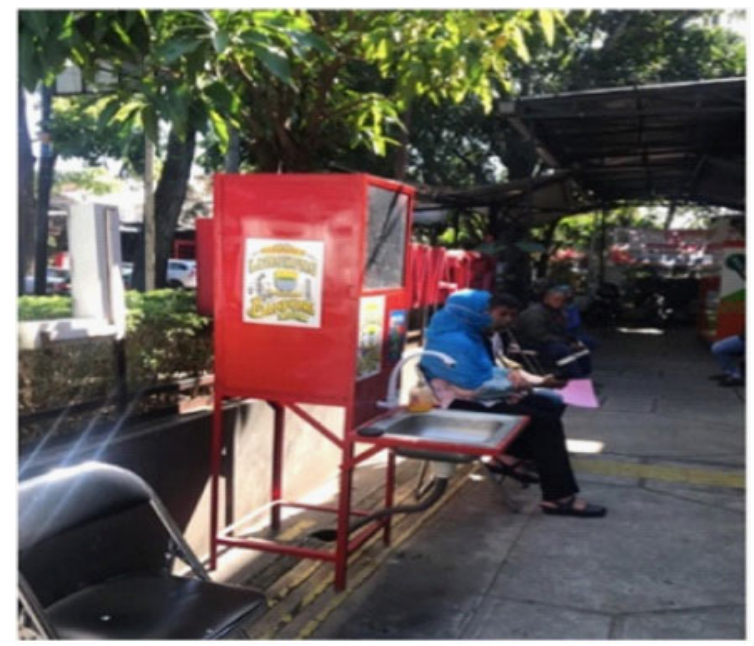

Figure 1. The old portable handwashing station.

The old portable handwashing station prior to this research was placed too far from the main entrance. Not only that, but the overall shape and design weren't very representative of the Lengkong Sub-District office. Moreover, the shape, function, and implemented material did not correspond to the health protocol, the faucet required physical contact to turn the water on, the soap dispenser also required physical contact to pump it out, and there also weren't any hand drying facilities in sight, making the surrounding ground wet with puddles from a lot of people's wet hands.

After analyzing the problems found by observing and giving interviews to the users, the new and improved handwashing station was made with supporting components like the multifunction rack with two separate water storage inside, one for clean water and the other for used dirty water. The zinc sink basin is equipped with a sensor-activated faucet, and on the side is a storage space for a soap dispenser, hand dryer, thermometer, and hand sanitizer dispenser. The design was made with the user target physics in mind, making it as ergonomic as possible for every age, gender, character, and everyday activity. Other than the ergonomic design for the users, this portable handwash also functions as a campaign tool to encourage people to wash their hands. The infographic design is made to appeal to wondering eyes even from afar. It is made so that even people from 5 meters away could see the information educating them of how important it is to wash their hands constantly to prevent the spread of COVID-19. The circulation problem is also fixed by putting the station nearer to the entrance, making the space for a queue longer so that the visitors have more space to follow the health protocol and avoid physical touch against each other. 


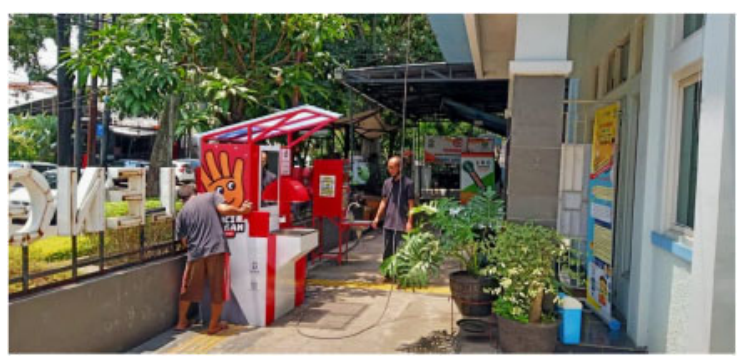

Figure 2. The new portable handwash station.

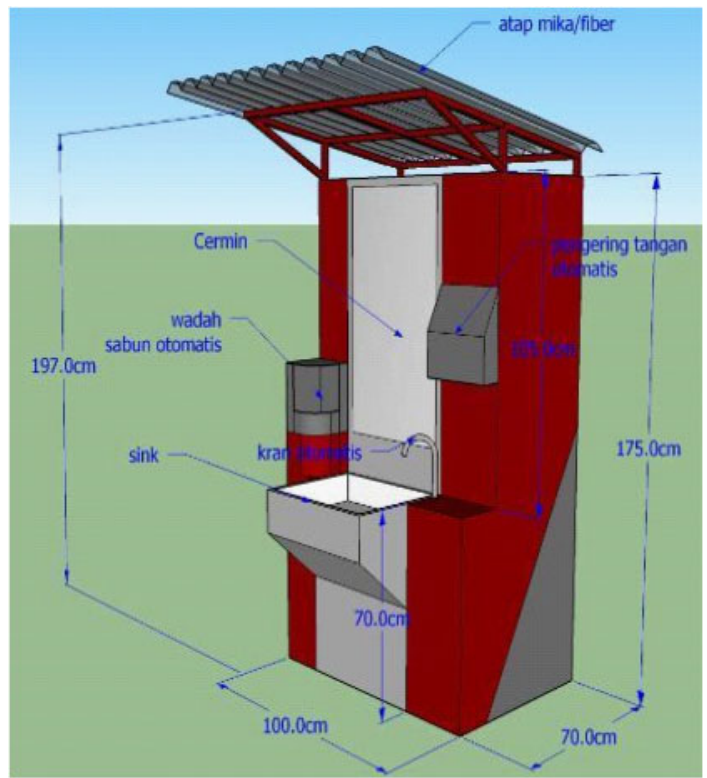

Figure 3. 3D visual of the new handwash station design.

The automatic touchless faucet, soap dispenser, and hand dryer minimizes, if not completely eliminates, cross contamination. Significantly improving the previous condition where everything needs physical contact to work. The roof is designed to keep the station shielded from direct rain, making it more sustainable for durability. Although even if it doesn't keep all the rain water away, the materials used are mostly rust-free recyclable stainless steel, and melamine-finished steel pipe, making it as water resistant as possible as an insurance for risks of being placed outdoor, exposed to the tropical rain and humidity of Indonesia. These materials are the most sustainable, considering all aspects like recyclability, transportability, durability, and functionality.

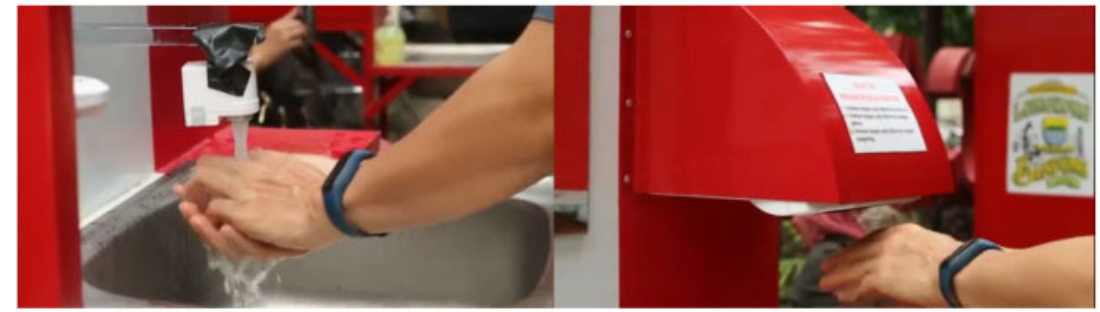

Figures 4 and 5. The touchless sensor activated water faucet and hand dryer. 


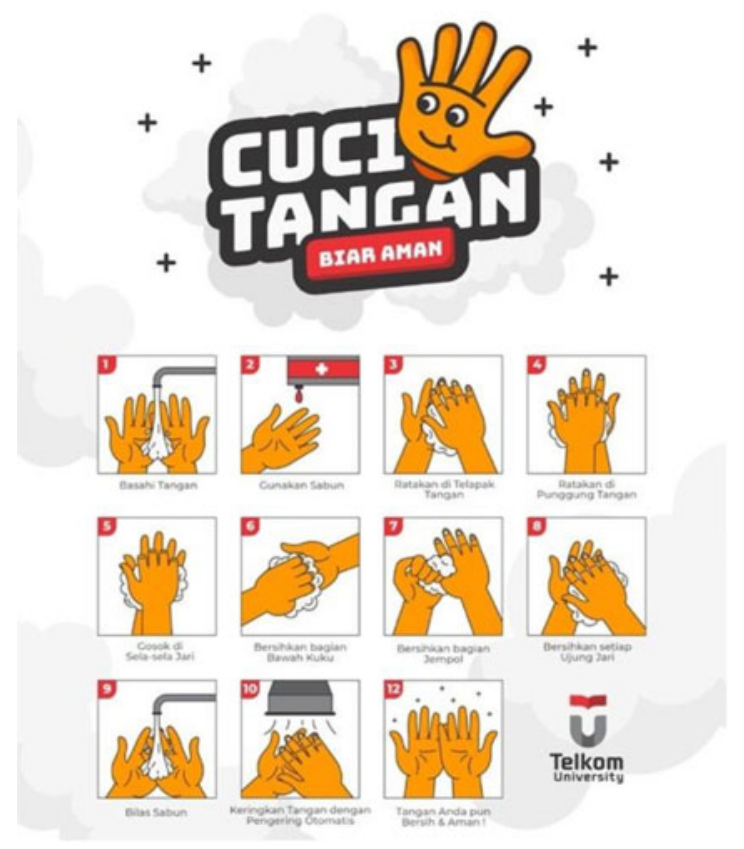

Figure 6. The design of the infographic diagram used in the campaign.

An infographic diagram is conveniently placed on the mirror, making it easy for the user to see so that it can serve its purpose to educate them about the proper way of handwashing. This way, the "The Cuci Tangan Biar Aman" campaign could be spread more effectively as the viewer of the infographic diagram could try the steps with the provided facility as they see it.

\section{CONCLUSION}

In an effort to stop the spread of the COVID-19 virus in the Lengkong Sub-District as well as to raise the awareness of the local people, the redesign of the portable handwashing station is in order. Coming from the characters of the product's users, the new product is made to be as efficiently functional as possible. Not only that, but the new product has several new modifications to minimize cross contamination from physical contact, it is also designed to be ergonomic for the local people, and after considering every aspects of sustainability, also the best material for this case of circumstance.

These improvements are proved to be more efficient than the old portable handwashing station. By considering its environmental character, it achieves beyond the original function of the handwashing station by also educating and encouraging the local people's awareness of the COVID-19 pandemic and how serious it is. The product also gives a passive imposing encouragement for its target users to use it without physically forcing anything. The obvious image of the campaign on this product could potentially make passerbys feel obligated to wash their hands, which is a good thing for society to be better handle the current pandemic.

\section{REFERENCES}

Calori, C. and Vanden-Eynden, D. 2015. Signage and Wayfinding Design: A Complete Guide to Creating Environmental Graphic Design Systems.

Fiksel, J. 1996. Design for Environment, Creating Eco-Efficient Products and Process, McGraw-Hill. 
Tanudireja, O. and Solahuddin, M. 2013. Ergonomics Viewed from Anthropometry at the Interior of Pizza-Hut Restaurant in East Surabaya. Journal of Intra. 1(2).

Teladan WargaNet. 2017. Design for Environment. https://warganetteladan.wordpress.com. (diakses tanggal Januari 2, 2021)

Ulrich, R.S., Zimring, C., Zhu, X., DuBose, J., Seo, H.B., Choi, Y.S., Quan, X., and Joseph, A. 2018. A review of the research literature on evidence-based healthcare design. Herd, 1(3): 61-125.

Zahra, Maysitha Fitri Az and Salayanti, S. 2016. Analysis of Visitor Circulation Patterns at Celebrity Fitness Transtudio Mall Bandung. Idealog: Indonesian Design Ideas and Dialogues 1.3:257-270. 